\title{
Autophagy is positively associated with the accumulation of myeloid-derived suppressor cells in 4-nitroquinoline-1-oxide-induced oral cancer
}

\author{
JIA-SHUN WU ${ }^{1}$, LI LI $^{2}$, SHA-SHA WANG ${ }^{1}$, XIN PANG $^{1}$, JING-BIAO WU ${ }^{1}$, SU-RUI SHENG ${ }^{1}$, \\ YA-JIE TANG $^{3}$, YA-LING TANG ${ }^{1}$, MIN ZHENG $^{2 *}$ and XIN-HUA LIANG ${ }^{1 *}$ \\ ${ }^{1}$ Department of Oral and Maxillofacial Surgery, State Key Laboratory of Oral Diseases and \\ National Clinical Research Center for Oral Diseases, West China Hospital of Stomatology, \\ Sichuan University, Chengdu, Sichuan 610041; ${ }^{2}$ Department of Stomatology, Zhoushan Hospital, \\ Wenzhou Medical University, Zhoushan, Zhejiang 316021; ${ }^{3}$ Key Laboratory of Fermentation Engineering \\ (Ministry of Education), Hubei Provincial Cooperative Innovation Center of Industrial Fermentation, \\ Hubei Key Laboratory of Industrial Microbiology, Hubei University of Technology, Wuhan, Hubei 430068, P.R. China
}

Received April 3, 2018; Accepted September 13, 2018

DOI: $10.3892 / o r .2018 .6747$

\begin{abstract}
It has previously been demonstrated that autophagy and inflammation act synergistically to promote carcinogenesis. However, the precise roles of autophagy in multistep oral carcinogenesis are still unclear, particularly regarding its association with tumor inflammation. The present study established a 4NQO-induced oral cancer mouse model and investigated autophagy status in the multistep process of oral carcinogenesis using immunohistochemistry, western blotting and immunofluorescence staining. Furthermore, the number of $\mathrm{Gr}-1^{+} \mathrm{CD} 11 \mathrm{~b}^{+}$myeloid derived suppressor cells (MDSCs) and $\mathrm{CD}^{+}{ }^{+}$Foxp $^{+}$regulatory $\mathrm{T}$ cells (Tregs) during oral carcinogenesis and the association with autophagy status was also examined. The results revealed that the expression of
\end{abstract}

Correspondence to: Professor Xin-Hua Liang, Department of Oral and Maxillofacial Surgery, State Key Laboratory of Oral Diseases and National Clinical Research Center for Oral Diseases, West China Hospital of Stomatology, Sichuan University, 14, Sec. 3, Renminnan Road, Chengdu, Sichuan 610041, P.R. China

E-mail: 1xh88866@scu.edu.cn

Dr Min Zheng, Department of Stomatology, Zhoushan Hospital, Wenzhou Medical University, 739 Dingshen Road, Lincheng Street, Zhoushan, Zhejiang 316021, P.R. China

E-mail: zm_iblue610@sina.com

*Contributed equally

Abbreviations: 4NQO, 4-nitroquinoline-1-oxide; OSCC, oral squamous cell carcinoma; MDSCs, Gr- $1^{+} \mathrm{CD} 11 \mathrm{~b}^{+}$myeloid derived suppressor cells; Tregs, CD4 ${ }^{+}$Foxp3 $^{+}$regulatory $\mathrm{T}$ cell; p62, p62/SQSTM1; TMA, tissue microarray.

Key words: autophagy, myeloid-derived suppressor cells, regulatory $\mathrm{T}$ cells, oral squamous cell carcinoma, 4-nitroquinoline-1-oxide autophagy biomarkers, including dihydrosphingosine 1-phosphate phosphatase LCB3 (LC3B), p62/SQSTM1 (p62) and Beclin 1 increased during 4NQO-induced carcinogenesis and in human oral cancer. The number of MDSCs and Tregs also increased during oral carcinogenesis. Furthermore, the expression of LC3B and p62 significantly correlated with the accumulation of MDSCs and the expression of Beclin 1 correlated with the increase of Tregs. These data indicated that autophagy may be activated by the tumor inflammation microenvironment during oral carcinogenesis.

\section{Introduction}

Oral squamous cell carcinoma (OSCC) is the sixth most commonly occurring cancer in the world and a lethal disease, with a 5-year survival rate of $\sim 50 \%$ (1). Despite continuing improvements in therapy, the poor prognosis of OSCC patients remains unsolved around the world. Carcinogenesis is a multistep process including initiation, promotion and progression, and oral cancer usually develops from premalignant lesions of oral mucosa into OSCC (2). It has been revealed that risk factors for human oral carcinogenesis include alcohol consumption, tobacco and human papillomavirus infection (3). However, the underlying molecular mechanism of dynamic oral carcinogenesis has not been completely elucidated.

Macroautophagy (autophagy) is an evolutionarily conserved and self-consumption process involved in preserving organelle function, removing cellular waste products and providing metabolic substrates $(4,5)$. It has been reported that autophagy is an evolving and multifaceted process during cancer initiation and progression (6). In normal cells, autophagy prevents excess reactive oxygen species, DNA damage and genome instability, known causes of cancer initiation and progression (7). In these contexts, autophagy likely serves as a tumor suppressor in the tumor initiation stages (8). However, in the late stages of tumorigenesis, autophagic responses maintain 
tumor metabolism and promote tumor cell survival. In this sense, autophagy exhibits a pro-oncogenic role $(6,8)$.

In addition to a cellular mechanistic role, autophagy has been demonstrated to orchestrate the tumor microenvironment by regulating the inflammation response (9-11). Autophagy enhances the processing and presentation of tumor antigens and thereby activates antitumor immunity (9). Martinez-Outschoorn et al (10) demonstrated that in a co-culture system, cancer cells produced numerous inflammatory mediators in a tumor microenvironment and further induced autophagy in adjacent fibroblasts via oxidative stress and nuclear factor (NF) $\kappa \mathrm{B}$-activation (10). This indicated that inflammation mediators in the tumor microenvironment contribute to tumor progression by activating the autophagy response $(10,11)$.

Hence, the present study established an oral cancer mouse model with 4-nitroquinoline-1-oxide (4NQO) and assessed the expression of autophagy markers dihydrosphingosine 1-phosphate phosphatase LCB3 (LC3B), p62/SQSTM1 (p62) and Beclin 1 at various stages of tongue lesions of these mice. Furthermore, the number of $\mathrm{Gr}-1^{+} \mathrm{CD} 11 \mathrm{~b}^{+}$myeloid derived suppressor cells (MDSCs) and $\mathrm{CD}^{+}{ }^{+} \mathrm{Foxp}^{+}$regulatory $\mathrm{T}$ cells (Tregs) during oral carcinogenesis and the association with autophagy status was also examined. The data will help to address the dynamic change of autophagy activity during multistage oral carcinogenesis and its association with inflammation.

\section{Materials and methods}

Ethics statement. All procedures involving mice were approved by the Subcommittee on Research and Animal Care of Sichuan University (WCHSIRB-D-2016-149, Chengdu, China). The written informed consents were obtained from participants through their signatures. The use of human tissue samples and clinical data was approved by the Institutional Ethics Committee of the West China Medical Center, Sichuan University (WCHSIRB-D-2012-097).

Experimental model. A total of 38 female wild-type C57BL/6 mice, eight weeks old, weighing 20-25 g were purchased from the Chengdu Dashuo Biological Technology Co., Ltd. (Sichuan, China). The mice were housed in State Key Laboratory of Oral Diseases West China Hospital of Stomatology (Sichuan University), five per cage, maintained at $22 \pm 1^{\circ} \mathrm{C}$ and within the range of $30-70 \%$ relative humidity with a 12 -h light/dark cycle. The animals were permitted free access to a normal chow (LabDiet with constant nutrition, Dashuo Co. Ltd., Chengdu, China) and drinking water provided in water bottles. A stock solution of 4-nitroquinoline-1-oxide (4NQO; Sigma-Aldrich; Merck KGaA, Darmstadt, Germany) was prepared at $0.5 \mathrm{mg} / \mathrm{ml}$ and added to the drinking water to obtain the working concentration. To avoid the decomposition of 4NQO, light avoidance precaution was taken. After a week of acclimation, mice were randomly assigned into three separate experimental groups: Control group $(n=10)$, low-4NQO group $(n=18)$, high-4NQO group $(n=20)$. In the experimental groups, the mice were given $100 \mu \mathrm{g} / \mathrm{ml}$ 4NQO (low-4NQO group) or $200 \mu \mathrm{g} / \mathrm{ml}$ 4NQO (high-4NQO group) in drinking water. Then, mice in low-4NQO and high-4NQO group were divided into 6 weeks, 10 weeks, 14 weeks or 18 weeks, as presented in Table I. Following corresponding time of 4NQO exposure, the animals in 4NQO-treated groups were switched to distilled water for 8 weeks. The animals in the control group received only distilled water.

At the end of the experimental period, mice were anesthetized using isoflurane, and blood was collected by vacutainer vials containing heparin. Tongue and spleen tissues were collected in each group and tongue tissues were then longitudinally bisected. One part of each tongue tissue was fixed in $10 \%$ buffered formalin at room temperature for $24 \mathrm{~h}$ and then embedded with paraffin. The other part was immediately snap-frozen and stored at $-80^{\circ} \mathrm{C}$ for western blotting or frozen with OCT for immunofluorescence staining.

Histopathological analysis. Sections $(4-\mu \mathrm{m})$ of tongue tissue from different groups were processed for hematoxylin and eosin (H\&E) staining. After deparaffinization and rehydration, the sections were stained with hematoxylin (OriGene Technologies, Inc., Rockville, MD, USA) at room temperature for $5 \mathrm{~min}$. Then the sections were differentiated in $1 \%$ hydrochloric acid alcohol for $2 \mathrm{sec}$ followed by incubation in ammonia water for $2 \mathrm{~min}$, and stained with eosin (OriGene Technologies, Inc.) at room temperature for $1 \mathrm{~min}$. Histopathological diagnosis was performed by an experienced oral pathologist in a blind manner, and the samples were classified into the following four types: Normal epithelium, mild-moderate dysplasia, severe dysplasia, and carcinoma, according to the criteria described by the World Health Organization (12). All histopathological examination was conducted using a light microscope (Olympus BX46; Olympus Corporation, Tokyo, Japan).

Tissue microarray (TMA) construction. The tissue microarray used for the present study included 52 oral squamous cell carcinoma (OSCC), 5 squamous cell papilloma and 5 normal mucosa specimens from the Department of Oral Pathology, West China Hospital of Stomatology, Sichuan University between 2013 and 2014. The OSCC samples used in the study were typical keratinizing-type, not verrucous or other variant types. There were 32 male and 20 female patients, and their ages ranged from 27 to 91 years, with a median age of 62 years. The diagnosis of these specimens was confirmed by pathologic examination. The tissue microarray slide was constructed as previously described (13). Briefly, based on the results of HE-stained tissue slides, formalin-fixed, paraffin-embedded tissue blocks were punched to obtain tissue cylinders with a $3 \mathrm{~mm}$ diameter containing representative tissue areas. Then the punched tissue cores were placed on a recipient block and arranged with an array pattern. Four- $\mu$ m-thick sections of TMA were produced for $\mathrm{H} \& \mathrm{E}$ and immunohistochemistry staining.

Immunohistochemical analysis. Paraffin-embedded sections at $4-\mu \mathrm{m}$ thickness were deparaffinized and rehydrated in graded ethanol series and distilled water. For antigen retrieval, slides were immersed in $0.01 \mathrm{M}$ sodium citrate buffer, $\mathrm{pH} 6.0$ in a water bath at $95^{\circ} \mathrm{C}$ for $30 \mathrm{~min}$. Endogenous peroxidases were inhibited by treatment with $3 \%$ hydrogen peroxide for $20 \mathrm{~min}$. After blocking with goat serum albumin (OriGene 
Table I. Incidence of tongue lesions in various 4-NQO-treated mice groups.

\begin{tabular}{|c|c|c|c|c|c|c|c|}
\hline \multirow[b]{2}{*}{ Group } & \multirow[b]{2}{*}{$\begin{array}{l}\text { No. of } \\
\text { mice }\end{array}$} & \multirow[b]{2}{*}{$\begin{array}{l}\text { Lesion } \\
\text { number }^{\mathrm{a}}\end{array}$} & \multirow[b]{2}{*}{$\begin{array}{c}\text { Lesion } \\
\text { size }(\mathrm{mm})^{\mathrm{b}}\end{array}$} & \multicolumn{3}{|c|}{ Dysplasia } & \multirow[b]{2}{*}{ Carcinoma (\%) } \\
\hline & & & & $\begin{array}{l}\text { Mild-moderate } \\
\text { dysplasia }(\%)\end{array}$ & $\begin{array}{c}\text { Severe } \\
\text { dysplasia }(\%)\end{array}$ & Total $(\%)$ & \\
\hline 14 weeks & 11 & 0.7 & 1.3 & 2/11 (18) & 4/11 (36.4) & $6 / 11(54.4)$ & $5 / 11(45.5)$ \\
\hline Low-dose 4NQO & 5 & 0.8 & 1.0 & $1 / 5 \quad(20)$ & $1 / 5 \quad(20)$ & $2 / 5 \quad(40)$ & $3 / 5 \quad(60)$ \\
\hline High-dose 4NQO & 6 & 0.7 & 1.6 & 1/6 (17.7) & $3 / 6 \quad(50)$ & 4/6 (67.7) & $2 / 6(33.3)$ \\
\hline 18 weeks & 8 & 1.6 & 1.3 & $4 / 8 \quad(50)$ & $2 / 8 \quad(25)$ & $6 / 8 \quad(75)$ & $2 / 8 \quad(25)$ \\
\hline Low-dose 4NQO & 4 & 1.7 & 1.5 & $1 / 4 \quad(25)$ & $1 / 4 \quad(25)$ & $2 / 4 \quad(50)$ & $2 / 4 \quad(50)$ \\
\hline high-dose 4NQO & 4 & 1.5 & 1.1 & $3 / 4 \quad(75)$ & $1 / 4 \quad(25)$ & 4/4 (100) & $0 / 4 \quad(0)$ \\
\hline 22 weeks & 9 & 2.0 & 1.6 & $1 / 9 \quad(11.1)$ & $2 / 9 \quad(22.2)$ & $3 / 9(33.3)$ & 6/9 (66.6) \\
\hline Low-dose 4NQO & 4 & 1.8 & 1.4 & $1 / 4 \quad(25)$ & $1 / 4 \quad(25)$ & $2 / 4 \quad(50)$ & $2 / 4 \quad(50)$ \\
\hline Hgh-dose 4NQO & 5 & 2.2 & 1.7 & $0 / 5 \quad(0)$ & $1 / 5 \quad(20)$ & $1 / 5 \quad(20)$ & $4 / 5 \quad(80)$ \\
\hline 26 weeks & 10 & 1.9 & 2.1 & $0 / 10 \quad(0)$ & $2 / 10(20)$ & $2 / 10(20)$ & $8 / 10(80)$ \\
\hline Low-dose 4NQO & 5 & 1.6 & 1.8 & $0 / 5 \quad(0)$ & $1 / 5 \quad(20)$ & $1 / 5 \quad(20)$ & $4 / 5 \quad(80)$ \\
\hline High-dose 4NQO & 5 & 2.2 & 2.4 & $0 / 5 \quad(0)$ & $1 / 5 \quad(20)$ & $1 / 5 \quad(20)$ & $4 / 5 \quad(80)$ \\
\hline Total & 38 & 1.5 & 1.9 & $7 / 38(18.4)$ & $10 / 38(26.3)$ & $17 / 38(44.7)$ & $21 / 38(55.3)$ \\
\hline
\end{tabular}

${ }^{a}$ The lesion number of each mouse was obtained and recorded, and then the sum of lesion number in each group was calculated. Average number of lesion was assessed by the formula: The sum of lesion number/mice number of each group. The mice were divided into four experimental

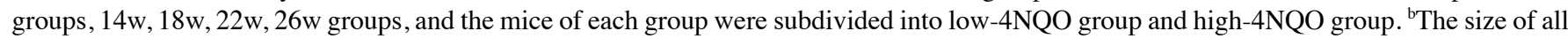
lesions in each mouse was obtained and recorded, and then the sum of lesion size in each group was calculated. Average number of lesion was assessed by the formula: The sum of lesion size/mice number of each group. The mice were divided into four experimental groups, 14w, 18w, $22 \mathrm{w}, 26 \mathrm{w}$ group, and the mice of each group were subdivided into low-4NQO group and high-4NQO group.

Technologies, Inc.) at room temperature for $20 \mathrm{~min}$, sections were incubated overnight at $4^{\circ} \mathrm{C}$ with anti-proliferating cell nuclear antigen (PCNA) monoclonal antibody (1:200; catalog no. ZM-0213, OriGene Technologies, Inc.), anti-LC3B antibody (1:200; catalog no. 14600-1-AP; Proteintech Group, Chicago, IL, USA), anti-p62 antibody (1:100; catalog no. WL02385; Wanleibio Co., Ltd., Shanghai, China) or anti-Beclin 1 mouse monoclonal antibody (1:100; catalog no. WL02508; Wanleibio Co., Ltd.). After rinsing with PBS, the slides were then incubated with biotinylated anti-mouse/rabbit IgG (catalog no. SP-9000; OriGene Technologies, Inc.) at room temperature for $15 \mathrm{~min}$, followed by incubation with peroxidase-streptavidin (catalog no. SP-9000; OriGene Technologies, Inc.) at room temperature for $15 \mathrm{~min}$. Finally, the slices were visualized with diaminobenzidine and nuclei were counterstained with hematoxylin at room temperature for $2 \mathrm{~min}$. As negative control specimens, PBS instead of the primary antibody was incubated.

One hundred epithelial cells or tumor cells from five representative fields of each section were randomly selected and evaluated by two independent researchers (JW, SW) under a light microscope (Olympus BX46; Olympus Corporation). The inconsistent results were re-evaluated by discussion until consensus was reached. The immunoreactivity of each protein was evaluated by combined assessment of the intensity and the percentage of positivity. The intensity was evaluated as: 0 (no staining), 1 (mild staining), 2 (moderate staining), 3 (strong staining). The proportion of stained cells was graded as: 0 (negative), 1 ( $0-10 \%$ positive), 2 (10-50\% positive) or 3 ( $>50 \%$ positive). The two variables were multiplied to provide a total score and the total score was categorized as negative (0-4) or positive ( $>4)$ for evaluation of the expression level in human patient samples.

Flow cytometry analysis. To prepare a single-cell suspension the spleen tissues were disaggregated mechanically by a Medimachine (Dako; Agilent Technologies GmbH, Waldbronn, Germany). Heparinized peripheral blood was diluted with equal PBS. Peripheral blood mononuclear cells (PBMCs) were isolated using Ficoll-Hypaque (eBioscience; Thermo Fisher Scientific, Inc., Waltham, MA, USA) density gradient centrifugation. For MDSCs analysis, spleen cell suspensions or PBMCs were incubated with $5 \mu$ l fluorescent monoclonal antibodies against Gr-1-PE, CD11b-FITC or isotype control (BD Biosciences, Franklin Lakes, NJ, USA) for $30 \mathrm{~min}$ in the dark at $4^{\circ} \mathrm{C}$. For Tregs analysis, cells were incubated with CD4-FITC or isotype control (BD Biosciences) followed by intracellular staining for Foxp3-PE (BD Biosciences). Finally, cells were washed and resuspended in PBS, and cell sorting occurred with flow cytometry (Becton Coulter, Inc., Brea, CA, USA) and analyzed using Winmdi2.9 software (Scripps Institute, San Diego, CA, USA).

Immunofluorescence staining. Frozen tissue specimens in OCT were cut into $8-\mu \mathrm{m}$ cryostat sections, fixed with acetone for $10 \mathrm{~min}$ and then brought to room temperature. The slides were incubated overnight at $4^{\circ} \mathrm{C}$ with anti-LC3B polyclonal antibody (1:200; catalog no. 14600-1-AP, Proteintech Group). The Rhodamine (TRITC) tagged anti-rabbit IgG (1:100; catalog no. ZF-0316; OriGene Technologies, Inc.) were diluted 
in $1 \%$ BSA in PBS and incubated with the sample for $1 \mathrm{~h}$ at $37^{\circ} \mathrm{C}$ in the dark, followed by counterstaining with DAPI to visualize the nuclei. The slides were observed under laser scanning confocal microscope (Olympus FluoView FV1000; Olympus Corporation) at x400 magnification,and excitation wavelength was $559 \mathrm{~nm}$ for detection of Rhodamine.

Western blot analysis. Total protein lysates were extracted from the mice tongue from each experimental group by using a Total protein lysate kit (catalog no. KGP250; Nanjing KeyGen Biotech Co., Ltd., Nanjing, China) according to the manufacturer's protocol. Protein concentration was quantified using the bicinchoninic acid assay (catalog no. KGP902; Nanjing KeyGen Biotech Co., Ltd., and $30 \mu \mathrm{g}$ of total protein was subjected to $12 \%$ SDS-PAGE. The fractionated samples were transferred to polyvinylidene difluoride membranes (EMD Millipore, Billerica, MA, USA), immersed in 5\% blotto at room temperature for 60 min to block non-specific binding and then incubated with anti-GAPDH antibody (1:5,000; catalog no. 10494-1-AP; Proteintech Group), anti-LC3B antibody (1:1,000; catalog no. 14600-1-AP; Proteintech Group), anti-P62 antibody (1:500; catalog no. WL02385; Wanleibio Co., Ltd.) and anti-Beclin 1 antibody (1:500; catalog no. WL02508; Wanleibio Co., Ltd.) overnight at $4^{\circ} \mathrm{C}$. The membranes were then incubated with the HRP-conjugated goat anti-rabbit IgG (1:5,000; catalog no. SA00001-2; Proteintech Group) for $1 \mathrm{~h}$ at room temperature. The specific bands were detected using the Immobilon Western Chemiluminescent HRP Substrate detection kit (EMD Millipore). The intensities of the protein bands were quantified with Quantity One 4.5.0 software (Bio-Rad Laboratories, Inc., Hercules, CA, USA).

Statistical analysis. Data were analyzed using SPSS software, version 22.0 (IBM SPSS, Armonk, NY, USA) and GraphPad Prism (version 5.03; GraphPad Software, Inc., La Jolla, CA, USA). The normally distributed quantitative data were expressed as the mean \pm standard deviations and were compared using one-way analysis of variance. The SNK test was performed for multiple testing among all groups. Comparisons of the positive rates of autophagy marker expression in human tissues were performed using Fisher's exact test and Bonferroni correction was performed for multiple testing (data not shown). $\mathrm{P}<0.05$ was considered to indicate a statistically significant difference. Pearson correlation analysis was performed to evaluate the correlation between autophagy marker expression and the number of MDSCs and Tregs. Immunohistochemical analysis, flow cytometry analysis, immunofluorescence staining and western blot analysis were repeated at least three times.

\section{Results}

Characteristics of mouse oral tumor model in macroscopic examinations. In the present study, mice were exposed to low or high doses of 4NQO for different time-periods and returned to normal drinking water for 8 weeks. Visible and gross lesions of the oral cavity were observed both in low-dose and high-dose 4NQO groups after a period of 6 weeks 4NQO treatment and 8 weeks observation. At 14 weeks, the average lesion number and lesion size of low-dose $4 \mathrm{NQO}$-treated mice were
0.8 and $1 \mathrm{~mm}$ respectively, and 0.7 and $1.6 \mathrm{~mm}$ in high-dose 4NQO-treated mice (Table I). At 26 weeks, the average lesion number and lesion size of low-dose 4NQO-treated mice were 1.6 and $1.8 \mathrm{~mm}$ respectively, and 2.2 and $2.4 \mathrm{~mm}$ in high-dose 4NQO-treated mice. This indicated that lesion sizes and number in each mouse increased with the increase of $4 \mathrm{NQO}$ exposure duration. However, none of the control mice exhibited visible changes during the period of observation $(n=10)$.

Histopathological analysis and immunohistochemical staining of PCNA. Histological examination of 4NQO-induced lesion tissues was conducted by a trained pathologist blinded to the sample identities. As expected, 4NQO-treated mice induced oral carcinogenesis with a well-defined progression from normal epithelia, through dysplasia of different severity to early invasive carcinoma (Fig. 1A). Histopathologically, the tumor lesions were usually squamous cell carcinoma of well-differentiated or moderately-differentiated type with typical keratin pearl formation. A few of the tumor lesions exhibited a papillary surface configuration and spread into the submucosa and underlying muscle layer. At 14 weeks, $40 \%$ low-dose 4NQO-treated mice exhibited dysplasia, and $60 \%$ exhibited squamous cell carcinoma (SCC), whereas $67.7 \%$ high-dose 4NQO-treated mice exhibited dysplasia lesion, and 3.3\% showed SCC. At 18 weeks, 50\% low-dose 4NQO-treated mice showed squamous cell carcinoma (SCC), whereas no high-dose 4NQO-treated mice showed SCC. At 26 weeks, $80 \%$ mice of both the low-dose 4 NQO group and high-dose 4NQO group showed SCC. The histopathological analysis was summarized in Table I.

PCNA is a marker of cell proliferation and the PCNA expression in mouse tongues was detected by immunohistochemistry. In the control group, PCNA expression was weakly observed only in the basal layer and suprabasal layers of tongue epithelium. However, PCNA expression was markedly increased in the dysplasia and SCC groups (Fig. 1B).

Expression of LC3B, p62 and Beclin 1 in different periods of 4NQO-induced oral carcinogenesis. The present study examined LC3B expression, a common marker of autophagy, in tongue tissue of normal, mild-moderate dysplasia, severe dysplasia, and SCC groups. Immunohistochemical analysis demonstrated that LC3B was mainly expressed in the cytoplasm of the cells and infrequently in the perinuclear membrane and nucleus (Fig. 2A). By semiquantitative assessment of IHC staining, LC3B was highly expressed in dysplasia epithelia and SCC compared to control group, and LC3B levels in SCC were increased compared with dysplasia epithelia ( $\mathrm{P}<0.05$; Fig. $2 \mathrm{~B}$ ). Additionally, immunofluorescence assessment revealed that LC3B puncta (representing autophagosomes) formation also increased during oral carcinogenesis (Fig. 2C). These results indicated that increased $\mathrm{LC} 3 \mathrm{~B}$ levels were associated with tongue carcinogenesis progression. Then, the present study further tested the isoform conversion of LC3, another indicator of autophagosome formation during 4NQO-induced tongue carcinogenesis. The result of the western blot analysis demonstrated that the LC3B-II expression level was upregulated in SCC compared with normal and dysplasia tissues (Fig. 2D). Taken together, the increased LC3B expression 
A

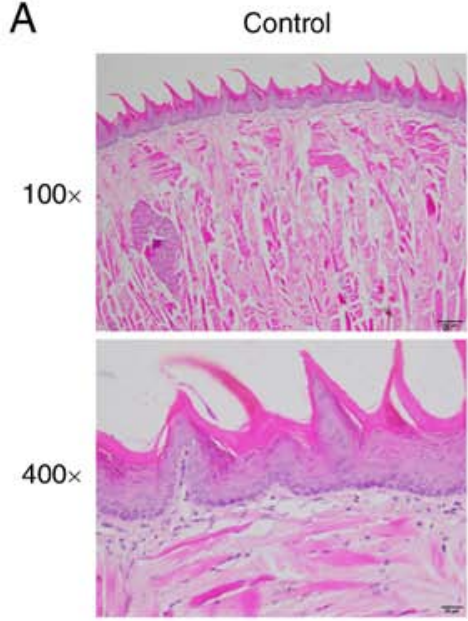

B

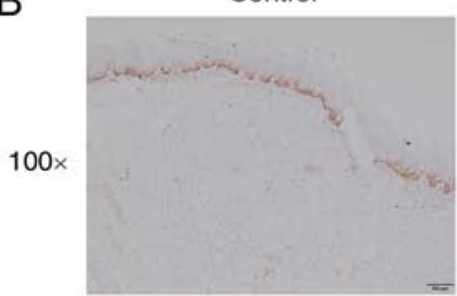

$400 \times$

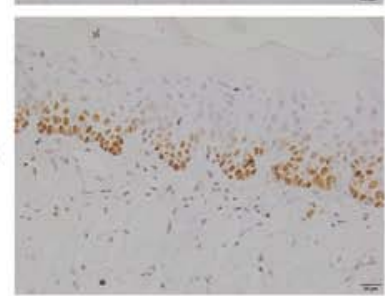

Mild-moderate dysplasia
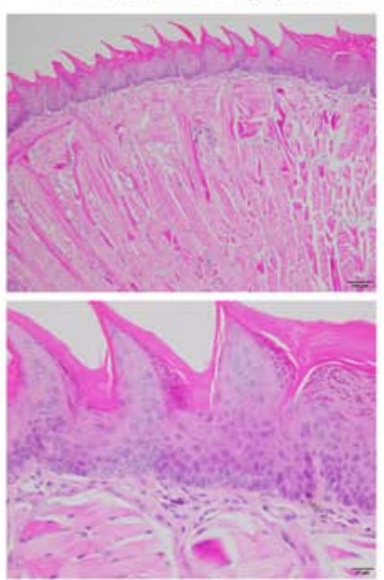

Mild-moderate dysplasia
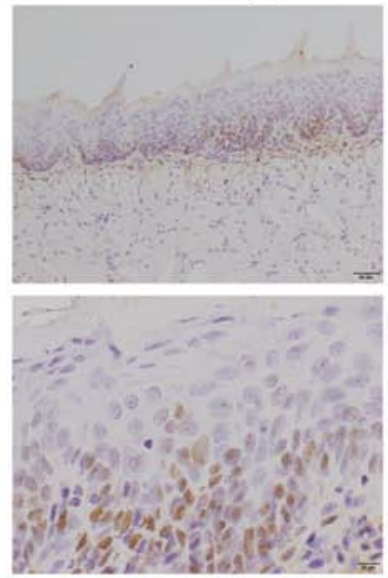

Severe dysplasia
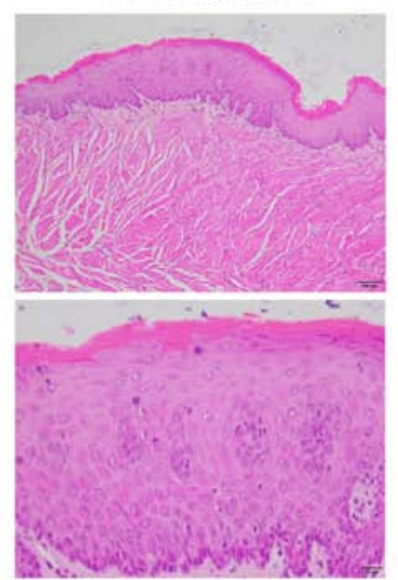

Severe dysplasia
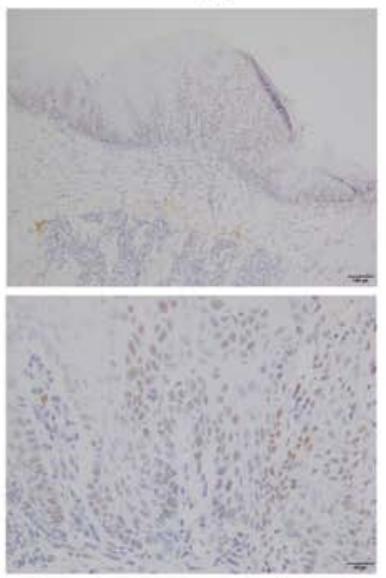

SCC

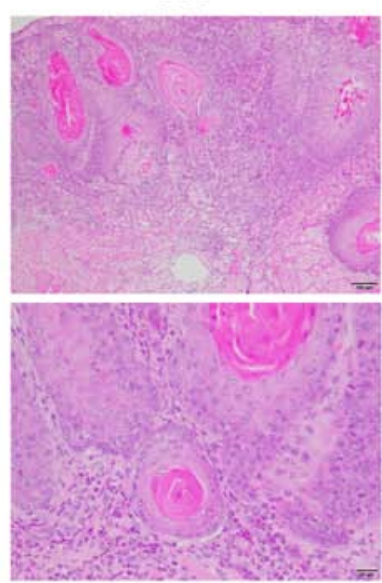

SCC
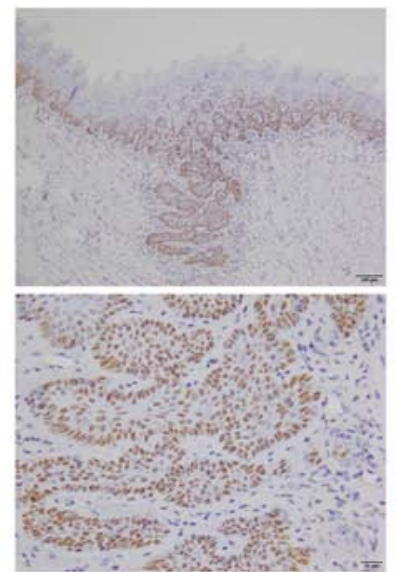

Figure 1. Histopathology of tongue mucosa from the mice treated with 4-nitroquinoline-1-oxide or vehicle. Representative tissue sections of (A) hematoxylin and eosin and (B) immunohistochemical detection of proliferating cell nuclear antigen of normal mucosa (control group), mild-moderate dysplasia, severe dysplasia, and invasive SCC. Scale bars of the top and bottom panels in the images are 100 and $20 \mu \mathrm{m}$, respectively. Magnification, $\mathrm{x} 100$ and x400. SCC, squamous cell carcinoma.

suggested that autophagosome formation increased during oral carcinogenesis.

p62, a ubiquitin-binding scaffold protein, serves as an autophagy substrate and cargo adapter that can be selectively degraded by autophagy. To identify the level of autophagy flux, p62 expression was assessed by immunohistochemistry and western blot analysis at various stages of $4 \mathrm{NQO}$-induced tongue carcinogenesis. p62 was primarily expressed in the cytoplasm and infrequently in the nucleus, consistent with the finding that p62 can shuttle between nucleus and cytoplasm (14). Normal tongue epithelium exhibited weak p62 expression, which was predominantly detected in the stratum spinosum of stratified squamous epithelia. In dysplastic epithelium and SCC, increased cytoplasmic expression of p62 was observed. Furthermore, SCC exhibited increased cytoplasmic expression of p62 compared with dysplastic epithelium (Fig. 2A and B). Western blot analysis of tongue tissues from different groups also revealed that the levels of p62 expression increased during oral carcinogenesis (Fig. 2D).

Beclin 1, an essential regulator of autophagy, functions by interaction with LC3B and p62. Immunohistochemistry results revealed that Beclin 1 was localized dominantly in the cytoplasm, although perinuclear expression was also observed. In normal tongue epithelium, Beclin 1 was weakly expressed, whereas strong expression of Beclin 1 was observed in dysplastic epithelium and SCC (Fig. 2A and B). Western blot analysis of tongue tissues from different groups also revealed that the expression levels of p62 increased during oral carcinogenesis (Fig. 2D).

Furthermore, the present study also evaluated expression of autophagy related 7 (Atg7), a key regulator of autophagosome maturation, in 4NQO-induced mice tongue carcinogenesis by western blotting. Consistent with other autophagy markers, elevated Atg7 expression was also detected in dysplastic epithelium and SCC (Fig. 2D). Taken together, the autophagy level increased during the progressive stages of $4 \mathrm{NQO}$-induced tongue carcinogenesis.

Expression of autophagy markers in human oral cancer. The present study investigated the protein level of autophagy-associated genes in resection specimens from 5 normal mucosa, 5 squamous cell papilloma and 52 OSCC patients by a tissue microarray and immunohistochemical staining (Fig. 3A). Compared with negative expression of autophagy markers 
A LC3B Normal mucosa

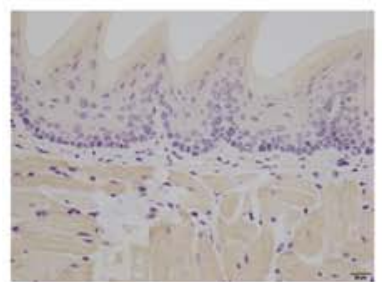

p62

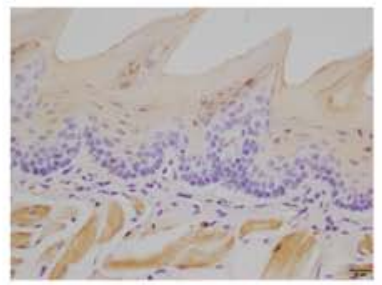

Beclin 1
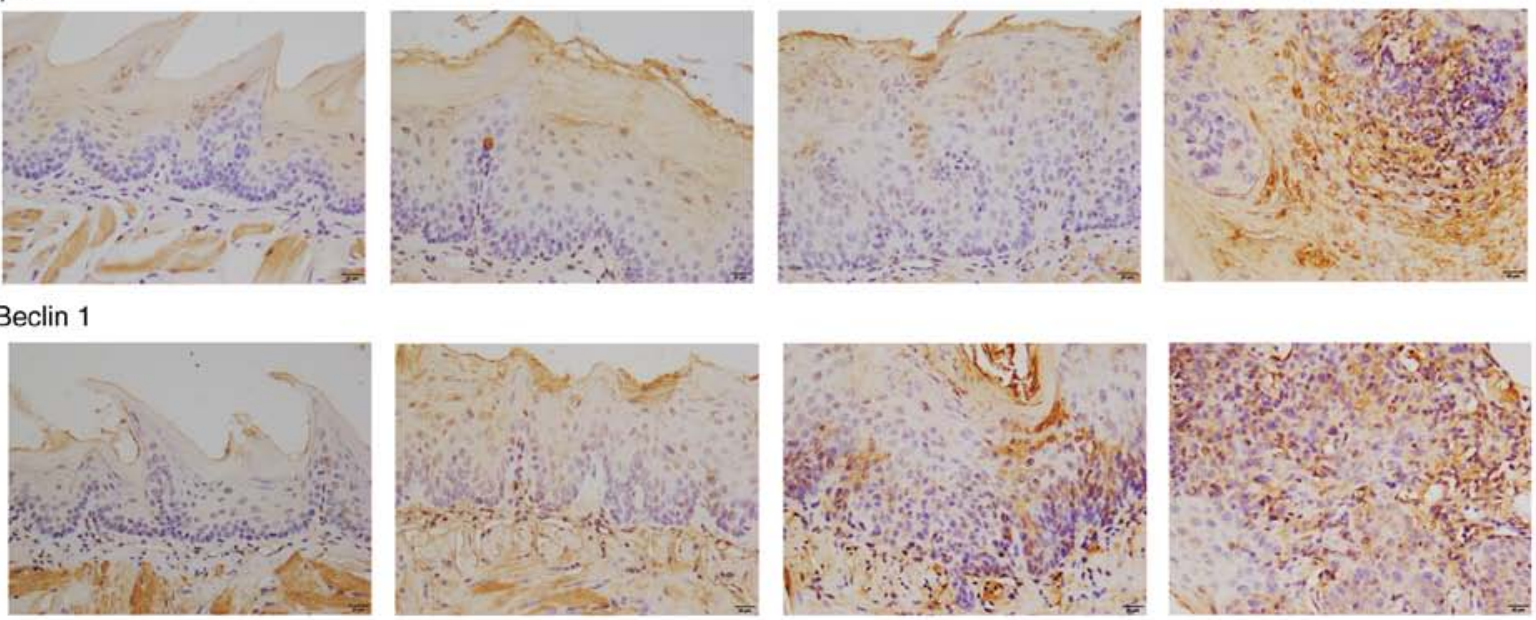

B

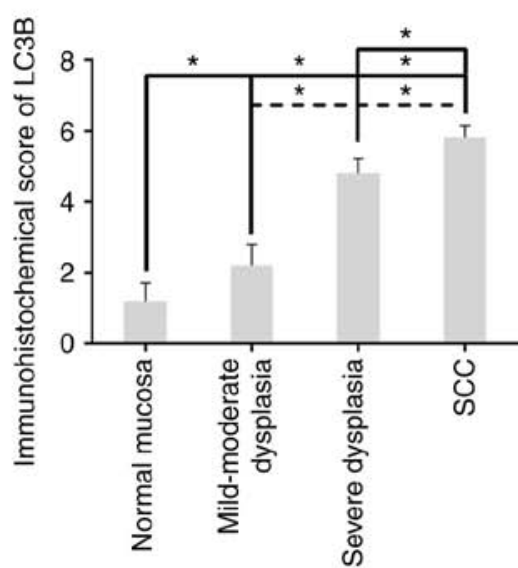

C

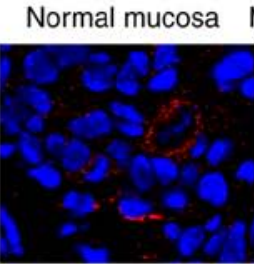

ญ్

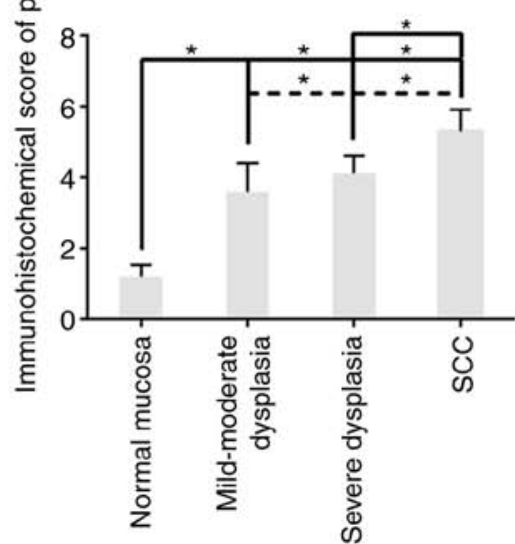

SCC

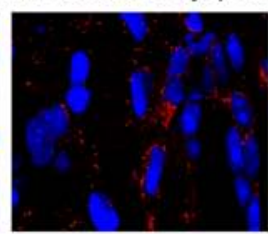

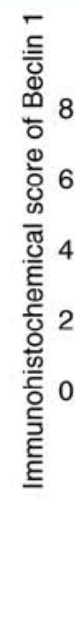

$\mathrm{D}$

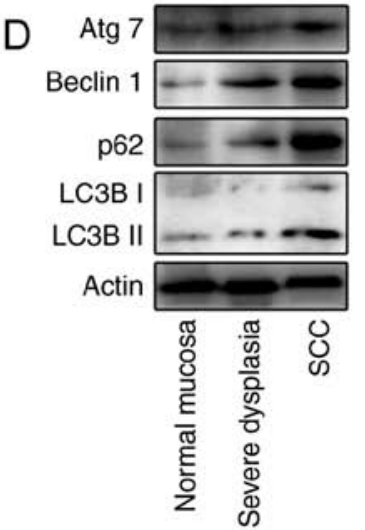

Figure 2. Expression levels of LC3B, p62, Beclin 1 and Atg7 during 4NQO-induced oral carcinogenesis. (A) Representative immunohistochemical analysis of LC3B, p62 and Beclin 1 expression in sectioned tissue samples from the 4NQO-treated mice. All images were taken at x400 magnification with $20 \mu \mathrm{m}$ scale bars (B) Semiquantitative staining analysis showed that the expression of LC3B, p62 and Beclin 1 was gradually upregulated from normal mucosa, mild-moderate dysplasia, severe dysplasia, and SCC. (C) Immunofluorescent staining revealed LC3 puncta in tongue tissue of 4NQO-treated mice accumulated during oral carcinogenesis. (D) Representative western blot images displaying $30 \mu \mathrm{g}$ of total protein extracted from the tongue tissue of each experimental group showed increased levels of LC3, p62, Beclin 1 and Atg7 in dysplasia and SCC groups, compared with normal mucosa group. Data are expressed as the mean \pm standard deviation. ${ }^{*} \mathrm{P}<0.05$. LC3B, dihydrosphingosine 1-phosphate phosphatase LCB3; p62, p62/SQSTM1; Atg7, autophagy related 7; SCC, squamous cell carcinoma; 4NQO, 4-nitroquinoline-1-oxide. 
A

$40 \times$

$400 \times$

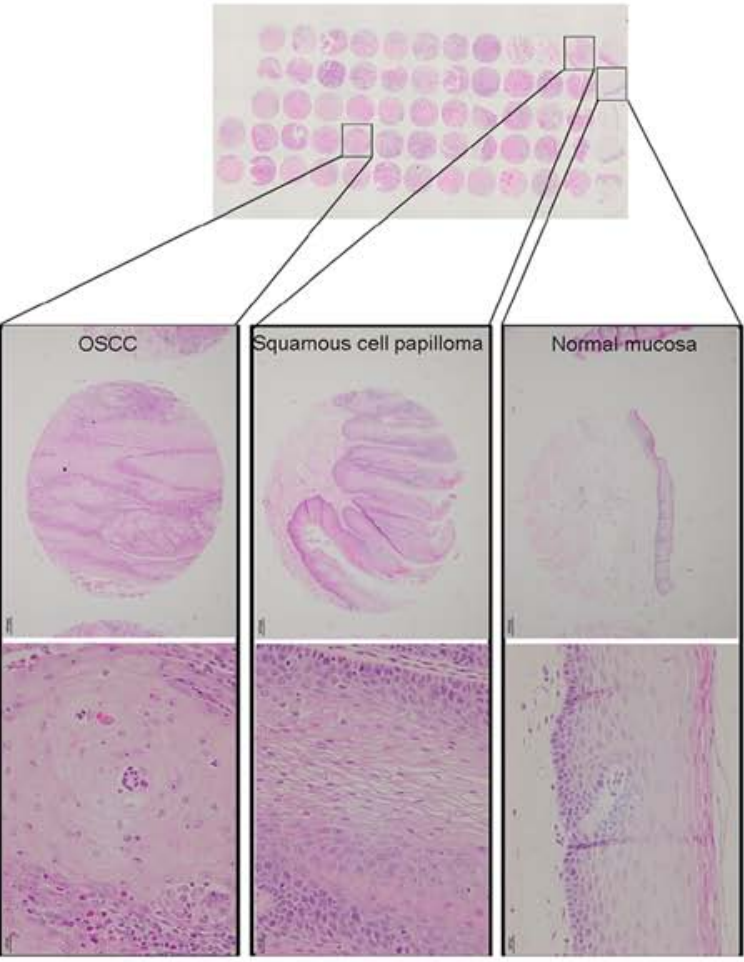

C

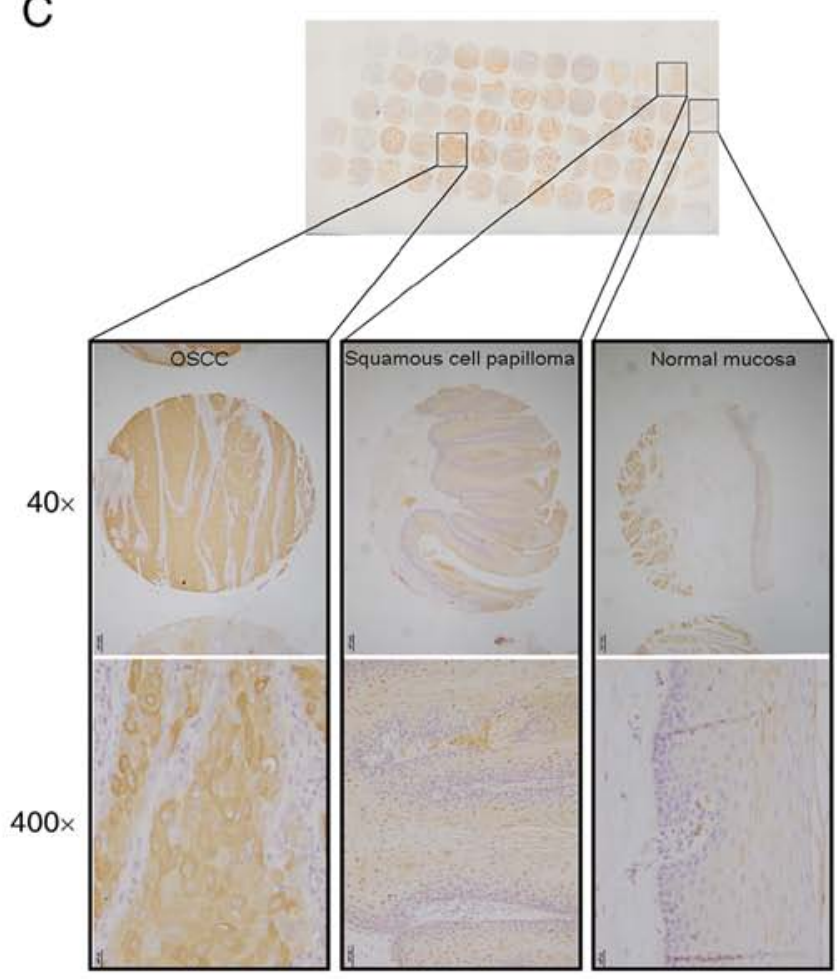

B

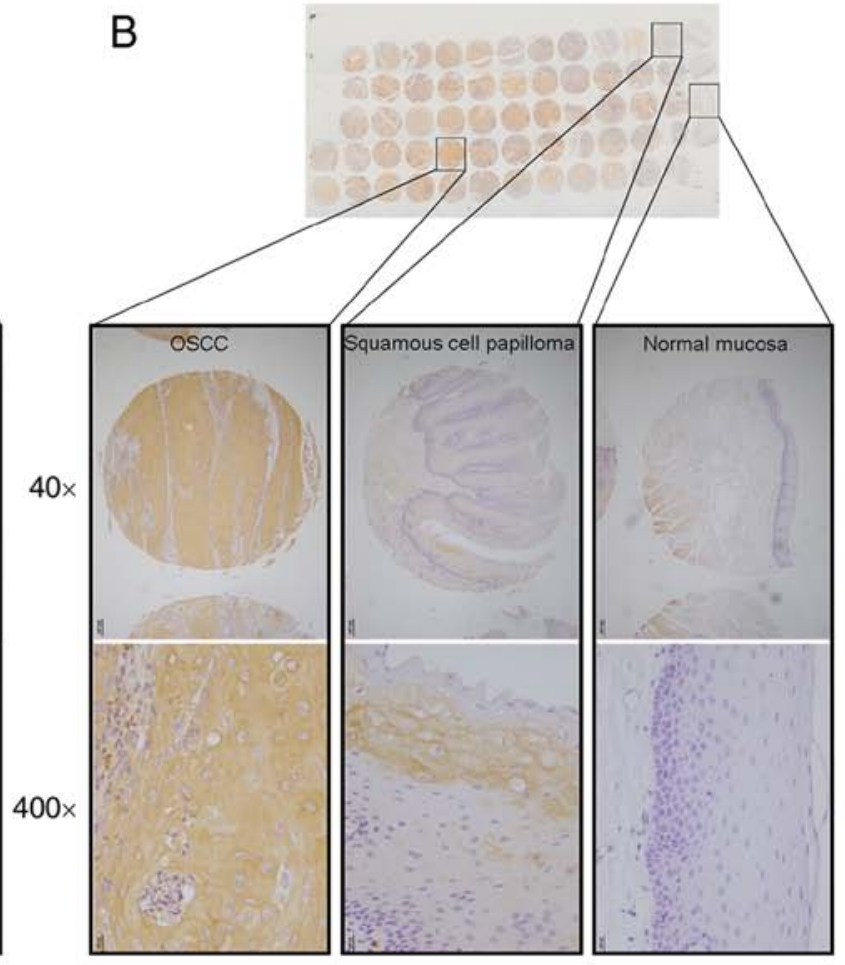

D

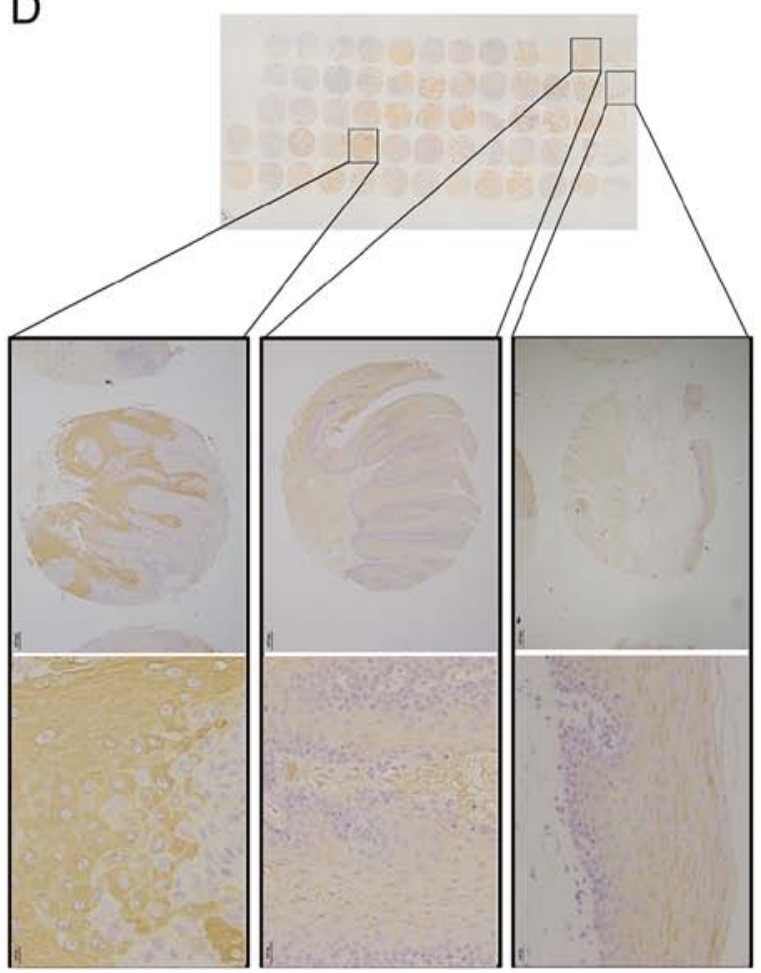

Figure 3. Expression of LC3B, p62 and Beclin 1 in human oral cancer. (A) Hematoxylin and eosin image displayed a tissue microarray analysis tissue containing 52 OSCC, 5 squamous cell papilloma and 5 normal mucosa specimens. Representative immunohistochemical analysis of (B) LC3B, (C) p62 and (D) Beclin 1 expression showed that these markers were upregulated in human squamous cell papilloma and OSCC compared with normal mucosa. Scale bars of the top and bottom panels in the images are 200 and $20 \mu \mathrm{m}$ respectively. Magnification, x100 and x400. LC3B, dihydrosphingosine 1-phosphate phosphatase LCB3; p62, p62/SQSTM1; OSCC, oral squamous cell carcinoma.

in normal mucosa specimens, OSCC specimens exhibited stronger immunohistochemical staining (Fig. 3B-D). Specifically, $86.3 \%, 70.6$ and $78.4 \%$ OSCC specimens showed LC3B, p62 and Beclin 1 positive expression, respectively. Notably, squamous cell papilloma showed a higher positive rate of LC3B, p62 and Beclin 1 (20\%, 40\%, 20\% respectively) compared with normal mucosa, however this was decreased compared with OSCC (data not shown). These results suggested that autophagy was associated with human OSCC progression. 
A
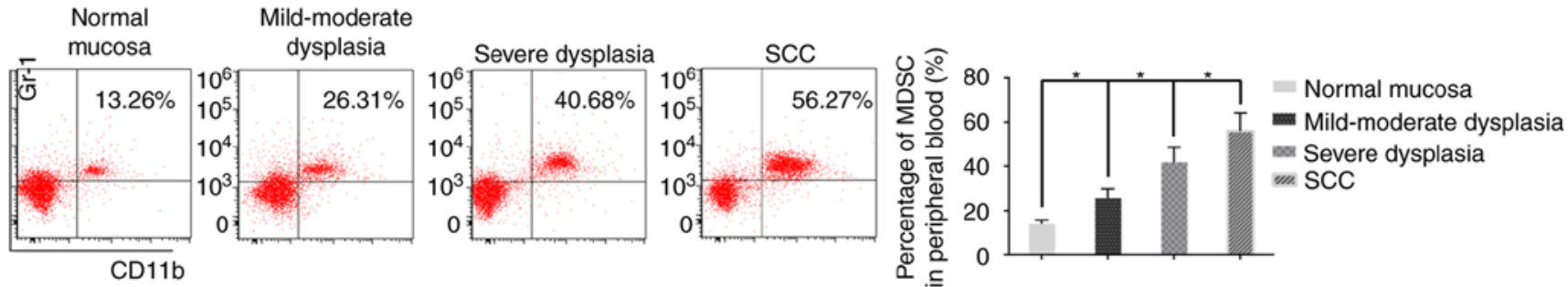

$\mathrm{B}$
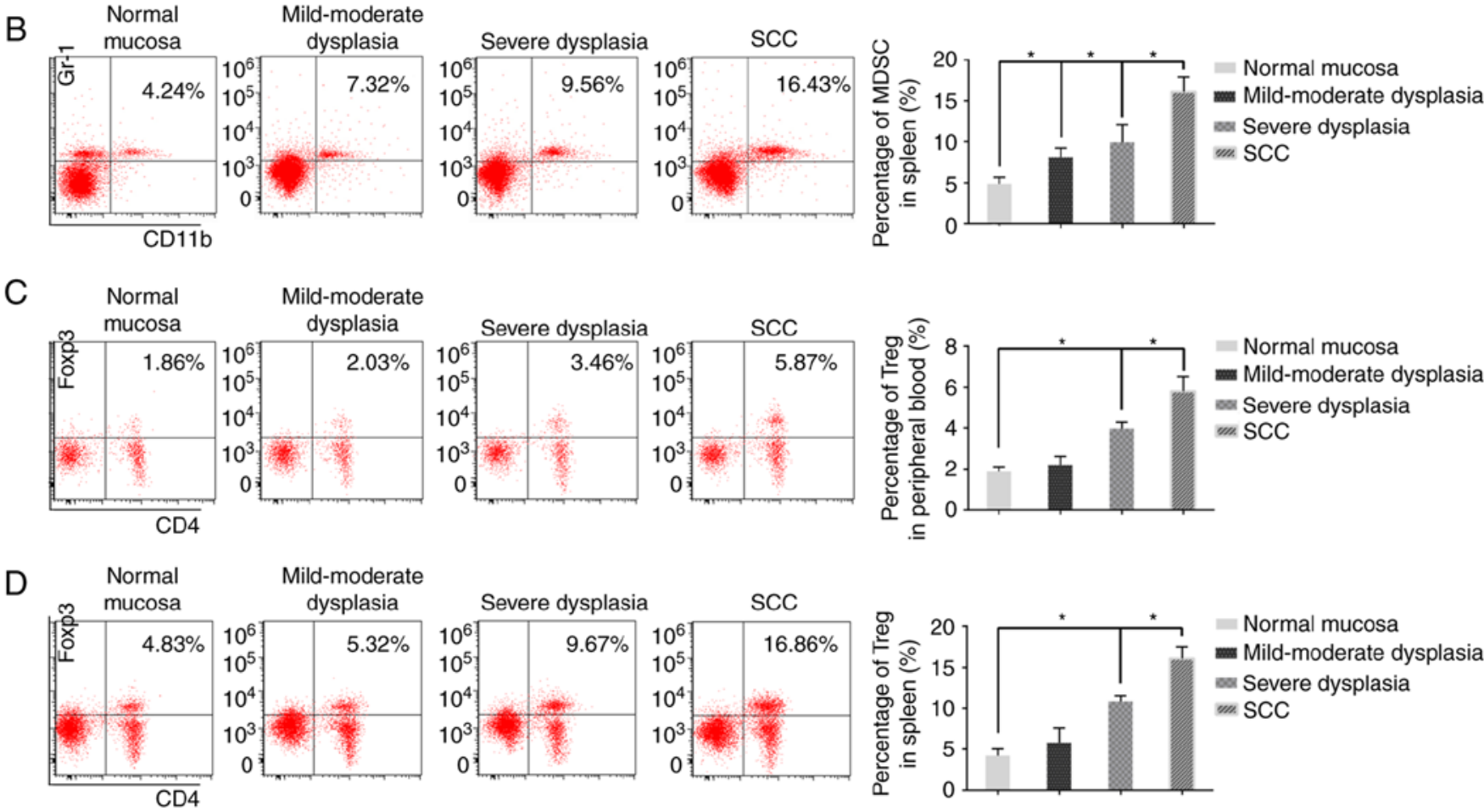

Normal mucosa Mild-moderate dysplasia Severe dysplasia $m$ SCC

Figure 4. Flow cytometric analysis of the number of MDSCs and Tregs in 4NQO-treated mice. Representative flow cytometry plots of MDSCs in (A) blood and (B) spleen tissues of normal mice, mild-moderate dysplasia, severe dysplasia, and tumor-bearing mice. Representative flow cytometry plots of Tregs from (C) blood and (D) spleen tissues of normal mice $(n=5)$, mild-moderate dysplasia $(n=6)$, severe dysplasia $(n=6)$, and tumor-bearing mice $(n=12)$. Data are expressed as the mean \pm standard deviation. ${ }^{*} \mathrm{P}<0.05$. MDSCs, Gr-1+CD11b+ myeloid derived suppressor cells; Tregs, CD4+ Foxp3+ regulatory $\mathrm{T}$ cells. $\mathrm{SCC}$, squamous cell carcinoma; 4NQO, 4-nitroquinoline-1-oxide.

Number of MDSCs and Tregs in peripheral blood and spleen tissue of $4 N Q O$-treated mice at different stages of $4 N Q O$-induced oral carcinogenesis. To examine the number of MDSCs and Tregs in 4NQO-treated mice, peripheral blood and spleen cells were screened by flow cytometry. A substantial accumulation of MDSCs and Tregs was observed in the peripheral blood and spleens during oral carcinogenesis. It was revealed that the number of MDSCs in the peripheral blood and spleens gradually increased in mild-moderate dysplasia, severe dysplasia, and SCC groups compared with control group (Fig. 4A and B). A similar change in the Tregs number was observed in the peripheral blood and spleens of the control, mild-moderate dysplasia, severe dysplasia, and SCC groups (Fig. 4C and D).

Relationship between autophagy-associated proteins and inflammation during oral carcinogenesis. The present study used Pearson correlation analysis to evaluate the correlation between autophagy marker expression and the number of MDSCs and Tregs during oral carcinogenesis (data not shown). The expression levels of LC3B and p62 were positively associated with the number of MDSCs in the peripheral blood and spleen tissues, whereas the expression of Beclin 1 was closely associated with the number of Tregs in the peripheral blood and spleen tissues. These results indicated that the expression of autophagy-associated proteins appeared to be associated with tumor inflammation during oral carcinogenesis.

\section{Discussion}

It has been recognized that autophagy is closely associated with carcinogenesis (15). Previous evidence has revealed that inflammation in the tumor microenvironment can induce autophagy, which produces recycled nutrients to 'feed' anabolic cancer cells and maintain tumor cell survival (10). In the present study, the results revealed that the expression levels of LC3B, p62 and Beclin 1 and the number of MDSCs and Tregs increased during oral carcinogenesis. A close association was observed between the overexpression of autophagy biomarkers and the accumulation of myeloid derived suppressor cells. In addition, autophagy activation was also observed in squamous cell papilloma and OSCC patient specimens. These data indicated that autophagy may be activated by tumor inflammation microenvironment during oral carcinogenesis. To the best 
of the authors' knowledge, this is the first study to evaluate the role of autophagy in 4NQO-induced oral carcinogenesis, which was demonstrated to provide a favorable tumor microenvironment for oral carcinogenesis.

The 4NQO-induced oral tumorigenesis mouse model has been proven to provide an ideal model for studying tumor pathobiology during sequential progression of human oral cancer (16). Numerous studies have established the 4NQO-induced oral cancer mouse model by adding various does of $4 \mathrm{NQO}$ in drinking water, but the problems of time-consuming and slow effect of this mice model remain unsolved (17-19). In the present study, based on the histological analysis, continuous 4NQO exposure in the mouse model induced the multistage oral carcinogenesis lesions including different grades of dysplasia and squamous cell carcinoma, similar to human oral carcinogenesis. Consistent with previous studies, a long period (26 weeks) of 4NQO exposure increased the mice oral carcinogenesis rate compared with the short period (14 weeks) $(18,20,21)$. However, $200 \mu \mathrm{g} / \mathrm{ml} 4 \mathrm{NQO}$ exposure does not further accelerate oral carcinogenesis, although a similar lethality rate remains $(22,23)$. It therefore became evident that $100 \mu \mathrm{g} / \mathrm{ml}$ was an appropriate dose with which to induce mice oral cancer in this model and a higher dose cannot accelerate oral carcinogenesis. This is in line with most previous studies, in which the 4NQO dose used to treat mice is usually lower than $100 \mu \mathrm{g} / \mathrm{ml}(22,24,25)$. However, this result may be attributed to the small number of mice in the study, and further studies of larger sample size should be conducted in the future.

LC3 is considered a well-established marker of autophagy activity for monitoring autophagosome formation (26). Previous studies have reported that LC3 expression is elevated and positively associated with poor survival in many cancers (27-29). The present study demonstrated that LC3B expression was increased in premalignant lesion and squamous cell carcinoma of 4NQO-treated mice. Similarly, increased LC3B expression was also detected in human OSCC specimens. These were consistent with a previous study in which LC3B puncta formation exhibited an increasing trend from human normal oral mucosa, verrucous hyperplasia to OSCC (30). Additionally, high LC3 expression status in OSCC is closely associated with lymph node metastasis, advanced TNM stage and unfavorable outcome (31).

p62, as a selective substrate, is routinely used as a biomarker to monitor autophagy flux and p62 accumulates when autophagy is suppressed (32). The results revealed that normal tongue epithelia exhibited limited cytoplasmic p62 expression, whereas both 4NQO-induced squamous cell carcinoma and human OSCC exhibited increased expression, suggesting that p62 expression was upregulated during oral carcinogenesis (30). Although a previous study reported that no differences in p62 expression were observed among normal oral mucosa, verrucous hyperplasia, and OSCC, p62 has been found to be upregulated in several human cancers, including colorectal carcinoma, epithelial ovarian cancer and gliomas (30,33-35). p62 is considered an autophagy substrate and can be degraded by interaction with LC3 (32). However, high levels of p62 protein have been revealed to induce oncogenic transformation independent of its autophagy-associated functions (36). Valencia et al (37) demonstrated that in the tumor microenvironment, p62 can promote the inflammatory response via $\mathrm{NF}-\kappa \mathrm{B}$ activation and upregulation of $\mathrm{c}-\mathrm{Myc}$ genes by activating mechanistic target of rapamycin kinase complex 1 (37). Moreover, p62 also activates the nuclear factor, erythroid 2 like 2-dependent anti-oxidant response and thereby controls cell death and survival (38). Taken together, p62 may act as a pro-oncogenic regulator in oral carcinogenesis but the underlying mechanism is not clear.

Beclin 1 has been recognized as a central regulator of autophagy. In the present study, Beclin 1 expression was revealed to be upregulated during 4NQO-induced carcinogenesis. Similarly, Beclin 1 overexpression was also observed in papilloma and OSCC patient specimens. Consistent with the results of the present study, the accumulation of Beclin 1 has been found in breast, colon and ovarian cancer tissues $(29,39,40)$. Notably, increase of Beclin 1 has been reported to be a marker of poor prognosis in colon cancer (40). However, Hu et al (41) reported that Beclin 1 expression is decreased in oral tongue squamous cell carcinoma tissues relative to the matched non-cancerous tissues (41). Moreover, Beclin $1^{+/-}$mutant mice develop a large number of spontaneous tumors, including lymphomas, lung cancer and hepatocarcinoma $(42,43)$. The reason for these controversial outcomes in a variety of cancers may be that the role of autophagy depends upon intrinsic properties of the tumor type and upon the specific tumor environment.

Accumulating evidence has indicated that inflammation contributes to tumor initiation and progression (44). MDSCs and Tregs, two populations of inflammatory cells, notably increase in tumor-bearing mice and cancer patients and contribute to an immunosuppressive tumor microenvironment $(17,23)$. The present study observed a progressive increase in the proportion of MDSCs and Tregs in the spleens and peripheral blood during oral carcinogenesis. These results are consistent with previous studies $(17,23)$. Tregs are not considered a homogenous population. The multiple subpopulations of Tregs are distinguished by the expression of different cell surface markers, including FoxP3, CD4, CD25 and CD127 $(45,46)$. The present study examined the level of CD $4^{+}$Foxp $3^{+}$Tregs, which has been widely reported in previous studies (47-52). The multiple subpopulations of Tregs may play different roles in oral carcinogenesis and the authors hope to examine $\mathrm{CD} 4^{+}$ $\mathrm{CD} 25^{+} \mathrm{CD} 127$ low FoxP3 ${ }^{+}$Tregs in future studies.

Autophagy has been demonstrated to be activated by inflammation in the tumor microenvironment (10). In the present study, it was demonstrated that the expression of LC3B and p62 was positively associated with MDSCs number, and that the expression of Beclin 1 was closely associated with an increase in Treg number. This indicated that there was a correlation between autophagy and inflammation in oral carcinogenesis. However, the study cannot address how inflammation and autophagy act synergistically in carcinogenesis. One hypothesis is that autophagy can be activated in the inflammation microenvironment via activation of NLR Family Pyrin Domain Containing 3 and inflammasomes or oxidative stress-induced $\mathrm{NF}-\kappa \mathrm{B}$ activation (10). However, given that activated autophagy can suppress excessive inflammation by regulating the secretion of cytokines and chemokines and activate antitumor immunity by presentation of tumor antigens, further study to address this issue is necessary (9). 
In conclusion, the study demonstrated that the expression of LC3B, p62 and Beclin 1 was upregulated in 4NQO tongue carcinogenesis, accompanied with MDSCs and Tregs accumulation. The close correlation between autophagy markers and inflammatory cell number suggested that autophagy may be activated by tumor inflammation which provides a favorable tumor microenvironment for cancer development. However, temporal and adjustable autophagy inhibition studies in animal models are required in order to further confirm the roles of autophagy in oral carcinogenesis and its mechanisms in the tumor inflammation environment.

\section{Acknowledgements}

Not applicable.

\section{Funding}

The present study was supported by National Program on Key Research Project of China (grant no. 2016YFC0902700), National Natural Science Foundation of China grants (grant nos. 81672672, 81572650, 81772891, 81502357 and 81621062), Natural Science Foundation of Zhejiang Province (grant no. Q142114001), Zhoushan Science and Technology Bureau Project (grant no. 2014C3106) and by State Key Laboratory of Oral Diseases Special Funded Projects (2018).

\section{Availability of data and materials}

The majority of data generated or analyzed during this study are included in this published article. The data of expression of autophagy markers in human oral cancer and Pearson correlation analysis were not shown.

\section{Authors' contributions}

JSW conducted the study, carried out most of experiments and drafted the manuscript. XHL and MZ conceived the study and participated in its design. JSW, LL, SRS and XP assisted in development of methodology and acquisition of data. SSW and JBW performed the analysis or interpretation of data and drafted the manuscript. YJT and YLT participated in scoring of immunohistochemistry, performed data interpretation and revised the manuscript. All authors read and approved the final manuscript.

\section{Ethics approval and consent to participate}

All procedures involving mice were approved by the Subcommittee on Research and Animal Care (SRAC) of Sichuan University. The written informed consents were obtained from participants through their signatures. The use of human tissue samples and clinical data was approved by the Institutional Ethics Committee of the West China Medical Center, Sichuan University, China (WCHSIRB-D-2012-097).

\section{Patient consent for publication}

Informed consent for the publication was obtained from the participants.

\section{Competing interests}

The authors declare that they have no competing interests.

\section{References}

1. Petersen PE: Oral cancer prevention and control-the approach of the World Health Organization. Oral Oncol 45: 454-460, 2009.

2. Sarasin A: An overview of the mechanisms of mutagenesis and carcinogenesis. Mutat Res 544: 99-106, 2003.

3. Danaei G, Vander Hoorn S, Lopez AD, Murray CJ and Ezzati M; Comparative Risk Assessment collaborating group (Cancers): Causes of cancer in the world: Comparative risk assessment of nine behavioural and environmental risk factors. Lancet 366 : 1784-1793, 2005.

4. Mizushima N and Klionsky DJ: Protein turnover via autophagy: Implications for metabolism. Ann Rev Nutr 27: 19-40, 2007.

5. Green DR and Levine B: To be or not to be? How selective autophagy and cell death govern cell fate. Cell 157: 65-75, 2014.

6. White E: Deconvoluting the context-dependent role for autophagy in cancer. Nat Rev Cancer 12: 401-410, 2012.

7. Jin S: p53, Autophagy and tumor suppression. Autophagy 1: 171-173, 2005.

8. Rosenfeldt MT, O'Prey J, Morton JP, Nixon C, MacKay G, Mrowinska A, Au A, Rai TS, Zheng L, Ridgway R, et al: p53 status determines the role of autophagy in pancreatic tumour development. Nature 504: 296-300, 2013.

9. Zhong Z, Sanchez-Lopez E and Karin M: Autophagy, inflammation, and immunity: A troika governing cancer and its treatment. Cell 166: 288-298, 2016.

10. Martinez-Outschoorn UE, Whitaker-Menezes D, Lin Z, Flomenberg N, Howell A, Pestell RG, Lisanti MP and Sotgia F: Cytokine production and inflammation drive autophagy in the tumor microenvironment: Role of stromal caveolin-1 as a key regulator. Cell Cycle 10: 1784-1793, 2011.

11. Bonora M, Wieckowsk MR, Chinopoulos C, Kepp O, Kroemer G, Galluzzi L and Pinton P: Molecular mechanisms of cell death: Central implication of ATP synthase in mitochondrial permeability transition. Oncogene 34: 1608, 2015.

12. Kramer IR, Lucas RB, Pindborg JJ and Sobin LH: Definition of leukoplakia and related lesions: An aid to studies on oral precancer. Oral Surg Oral Med Oral Pathol 46: 518-539, 1978.

13. Vogel U: Overview on techniques to construct tissue arrays with special emphasis on tissue microarrays. Microarrays (Basel) 3: 103-136, 2014.

14. Pankiv S, Lamark T, Bruun JA, Øvervatn A, Bjørkøy G and Johansen T: Nucleocytoplasmic shuttling of p62/SQSTM1 and its role in recruitment of nuclear polyubiquitinated proteins to promyelocytic leukemia bodies. J Biol Chem 285: 5941-5953, 2010.

15. Galluzzi L, Pietrocola F, Bravo-San Pedro JM, Amaravadi RK, Baehrecke EH, Cecconi F, Codogno P, Debnath J, Gewirtz DA, Karantza V, et al: Autophagy in malignant transformation and cancer progression. EMBO J 34: 856-880, 2015.

16. Tang $\mathrm{XH}$, Scognamiglio $\mathrm{T}$ and Gudas LJ: Basal stem cells contribute to squamous cell carcinomas in the oral cavity. Carcinogenesis 34: 1158-1164, 2013.

17. Chu M, Su YX, Wang L, Zhang TH, Liang YJ, Liang LZ and Liao GQ: Myeloid-derived suppressor cells contribute to oral cancer progression in 4NQO-treated mice. Oral Dis 18: 67-73, 2012.

18. Zhao J, Wang Z, Han J, Qiu X, Pan J and Chen J: Increased frequency of $\mathrm{CD} 4^{+} \mathrm{CD} 25^{+}$FOXP ${ }^{+}$cells correlates with the progression of 4-nitroquinoline1-oxide-induced rat tongue carcinogenesis. Clin Oral Investig 18: 1725-1730, 2014.

19. Zhang M,QiaoX,ZhaoL,JiangLandRenF: Lactobacillus salivarius REN counteracted unfavorable 4-nitroquinoline-1-oxide-induced changes in colonic microflora of rats. J Microbiol 49: 877-883, 2011.

20. Kanojia D and Vaidya MM: 4-nitroquinoline-1-oxide induced experimental oral carcinogenesis. Oral Oncol 42: 655-667, 2006.

21. Vitale-Cross L, Czerninski R, Amornphimoltham P, Patel V, Molinolo AA and Gutkind JS: Chemical carcinogenesis models for evaluating molecular-targeted prevention and treatment of oral cancer. Cancer Prev Res (Phila) 2: 419-422, 2009. 
22. Tang XH, Osei-Sarfo K, Urvalek AM, Zhang T, Scognamiglio T and Gudas LJ: Combination of bexarotene and the retinoid CD1530 reduces murine oral-cavity carcinogenesis induced by the carcinogen 4-nitroquinoline 1-oxide. Proc Natl Acad Sci USA 111: 8907-8912, 2014.

23. Chen MF, Kuan FC, Yen TC, Lu MS, Lin PY, Chung YH, Chen WC and Lee KD: IL-6-stimulated CD11b+ CD14 HLA-DR-myeloid-derived suppressor cells, are associated with progression and poor prognosis in squamous cell carcinoma of the esophagus. Oncotarget 5: 8716-8728, 2014.

24. Zhang M, Wang F, Jiang L, Liu R, Zhang L, Lei X, Li J, Jiang J, Guo H, Fang B, et al: Lactobacillus salivarius REN inhibits rat oral cancer induced by 4-nitroquioline 1-oxide. Cancer Prev Res 6: 686-694, 2013.

25. Chen PT, Hsieh CC, Wu CT, Yen TC, Lin PY, Chen WC and Chen MF: $1 \alpha, 25$-dihydroxyvitamin D3 inhibits esophageal squamous cell carcinoma progression by reducing IL6 signaling. Mol Cancer Ther 14: 1365-1375, 2015.

26. Kabeya Y, Mizushima N, Ueno T, Yamamoto A, Kirisako T, Noda T, Kominami E, Ohsumi Y and Yoshimori T: LC3, a mammalian homologue of yeast Apg8p, is localized in autophagosome membranes after processing. EMBO J 19: 5720-5728, 2000.

27. Yoshioka A: LC3, an autophagosome marker, is highly expressed in gastrointestinal cancers. Int J Oncol 33: 461-468, 2008.

28. Schmitz KJ, Ademi C, Bertram S, Schmid KW and Baba HA: Prognostic relevance of autophagy-related markers LC3, p62/sequestosome 1, Beclin-1 and ULK1 in colorectal cancer patients with respect to KRAS mutational status. World J Surg Oncol 14: 189, 2016

29. Choi J, Jung W and Koo JS: Expression of autophagy-related markers beclin-1, light chain 3A, light chain 3B and p62 according to the molecular subtype of breast cancer. Histopathology 62 : 275-286, 2013

30. Liu JL, Chen FF, Lung J, Lo CH, Lee FH, Lu YC and Hung CH: Prognostic significance of p62/SQSTM1 subcellular localization and LC3B in oral squamous cell carcinoma. Br J Cancer 111: 944-954, 2014.

31. Tang JY, Hsi E, Huang YC, Hsu NC, Chu PY and Chai CY: High LC3 expression correlates with poor survival in patients with oral squamous cell carcinoma. Hum Pathol 44: 2558-2562, 2013.

32. Klionsky DJ, Abdelmohsen K, Abe A, Abedin MJ, Abeliovich H, Acevedo Arozena A, Adachi H, Adams CM, Adams PD, Adeli K, et al: Guidelines for the use and interpretation of assays for monitoring autophagy (3rd edition). Autophagy 12: 1-222, 2016.

33. Iwadate R, Inoue J, Tsuda H, Takano M, Furuya K, Hirasawa A, Aoki D and Inazawa J: High expression of SQSTM1/p62 protein is associated with poor prognosis in epithelial ovarian cancer. Acta Histochem Cytochem 47: 295-301, 2014.

34. Nakayama S, Karasawa H, Suzuki T, Yabuuchi S, Takagi K, Aizawa T, Onodera Y,Nakamura Y, Watanabe M,Fujishima F, et al: p62/sequestosome 1 in human colorectal carcinoma as a potent prognostic predictor associated with cell proliferation. Cancer Med 6: 1264-1274, 2017.

35. Zhao M, Xu H, Zhang B, Hong B, Yan W and Zhang J: Impact of nuclear factor erythroid-derived 2-like 2 and p62/sequestosome expression on prognosis of patients with gliomas. Hum Pathol 46: 843-849, 2015

36. Umemura A, He F, Taniguchi K, Nakagawa H, Yamachika S, Font-Burgada J, Zhong Z, Subramaniam S, Raghunandan S, Duran A, et al: p62, upregulated during preneoplasia, induces hepatocellular carcinogenesis by maintaining survival of stressed HCC-initiating cells. Cancer Cell 29: 935-948, 2016.

37. Valencia T, Kim JY, Abu-Baker S, Moscat-Pardos J, Ahn CS, Reina-Campos M, Duran A, Castilla EA, Metallo CM, Diaz-Meco MT and Moscat J: Metabolic reprogramming of stromal fibroblasts through $\mathrm{p} 62-\mathrm{mTORC} 1$ signaling promotes inflammation and tumorigenesis. Cancer Cell 26: 121-135, 2014.
38. Moscat J and Diaz-Meco MT: p62 at the crossroads of autophagy, apoptosis, and cancer. Cell 137: 1001-1004, 2009.

39. Zhao Y, Chen S, Gou WF, Xiao LJ, Takano Y and Zheng HC: Aberrant Beclin 1 expression is closely linked to carcinogenesis, differentiation, progression, and prognosis of ovarian epithelial carcinoma. Tumour Biol 35: 1955-1964, 2014.

40. Park JM, Huang S, Wu TT, Foster NR and Sinicrope FA: Prognostic impact of Beclin 1, p62/sequestosome 1 and LC3 protein expression in colon carcinomas from patients receiving 5-fluorouracil as adjuvant chemotherapy. Cancer Biol Ther 14: 100-107, 2013.

41. Hu Z, Zhong Z, Huang S, Wen H, Chen X, Chu H, Li Q and Sun C: Decreased expression of Beclin-1 is significantly associated with a poor prognosis in oral tongue squamous cell carcinoma. Mol Med Rep 14: 1567-1573, 2016.

42. Yue Z, Jin S, Yang C, Levine AJ and Heintz N: Beclin 1, an autophagy gene essential for early embryonic development, is a haploinsufficient tumor suppressor. Proc Natl Acad Sci USA 100: 15077-15082, 2003.

43. Qu X, Yu J, Bhagat G, Furuya N, Hibshoosh H, Troxel A, Rosen J, Eskelinen EL, Mizushima N, Ohsumi Y, et al: Promotion of tumorigenesis by heterozygous disruption of the beclin 1 autophagy gene. J Clin Invest 112: 1809-1820, 2003.

44. Elinav E, Nowarski R, Thaiss CA, Hu B, Jin C and Flavell RA: Inflammation-induced cancer: Crosstalk between tumours, immune cells and microorganisms. Nat Rev Cancer 13: 759-771, 2013.

45. Romano M, Tung SL, Smyth LA and Lombardi G: Treg therapy in transplantation: A general overview. Transpl Int 30: 745-753, 2017.

46. Edozie FC, Nova-Lamperti EA, Povoleri GA, Scottà C, John S, Lombardi G and Afzali B: Regulatory T-cell therapy in the induction of transplant tolerance: The issue of subpopulations. Transplantation 98: 370-379, 2014

47. Wei J,Long L, Yang K, Guy C, Shrestha S, Chen Z, Wu C, Vogel P, Neale G, Green DR and Chi H: Autophagy enforces functional integrity of regulatory $\mathrm{T}$ cells by coupling environmental cues and metabolic homeostasis. Nat Immunol 17: 277-285, 2016.

48. Zhang XX, Qiao YC, Li W, Zou X, Chen YL, Shen J, Liao QY, Zhang QJ, He L and Zhao HL: Human amylin induces $\mathrm{CD}^{+}{ }^{+} \mathrm{Foxp}^{+}$regulatory $\mathrm{T}$ cells in the protection from autoimmune diabetes. Immunol Res 66: 179-186, 2018.

49. Yin E, Matsuyama S, Uchiyama M, Kawai K and Niimi M: Graft protective effect and induction of $\mathrm{CD}^{+}{ }^{+} \mathrm{Foxp} 3^{+}$cell by thrombomodulin on allograft arteriosclerosis in mice. J Cardiothorac Surg 13: 48, 2018.

50. Sun IH, Oh MH, Zhao L, Patel CH, Arwood ML, Xu W, Tam AJ, Blosser RL, Wen J and Powell JD: mTOR complex 1 signaling regulates the generation and function of central and effector Foxp3 $3^{+}$regulatory T cells. J Immunol 201: 481-492, 2018.

51. Oyarce K, Campos-Mora M, Gajardo-Carrasco $\mathrm{T}$ and Pino-Lagos K: Vitamin $\mathrm{C}$ fosters the in vivo differentiation of peripheral $\mathrm{CD}^{+}{ }^{+}$Foxp3- $\mathrm{T}$ cells into $\mathrm{CD}^{+}{ }^{+} \mathrm{Foxp}^{+}$regulatory T cells but impairs their ability to prolong skin allograft survival. Front Immunol 9: 112, 2018.

52. Olguin JE, Medina-Andrade I, Molina E, Vázquez A, Pacheco-Fernández T, Saavedra R, Pérez-Plasencia C, Chirino YI, Vaca-Paniagua F, Arias-Romero LE, et al: Early and partial reduction in $\mathrm{CD}^{+}{ }^{+} \mathrm{Foxp}^{+}$regulatory $\mathrm{T}$ cells during colitis-associated colon cancer induces $\mathrm{CD} 4^{+}$and $\mathrm{CD} 8^{+} \mathrm{T}$ cell activation inhibiting tumorigenesis. J Cancer 9: 239-249, 2018.

This work is licensed under a Creative Commons Attribution-NonCommercial-NoDerivatives 4.0 International (CC BY-NC-ND 4.0) License. 